\title{
The Influence of Physical Activity on Quality of Life in Morbidly Obese Patients with Urinary Dysfunction
}

\author{
Jessica Eloa Poletto 1, *, Daniela Tezoto Rizzo ${ }^{1}$, Elaine Cristina Cândido ${ }^{1}$, Ana Maria Neder ${ }^{2}$, \\ Felipe David Mendonça Chaim², Elinton Adami Chaim²
}

${ }^{1}$ Medical Sciences College, University of Campinas, Campinas, Brazil

${ }^{2}$ Hospital of Clinics, University of Campinas, Campinas, Brazil

Email address:

jeloap@hotmail.com(J. E. Poletto),dvtezoto@hotmail.com (D. T. Rizzo), elainecris_99@yahoo.com.br (E. C. Cândido), ananeder@unicamp.br(A. M. Neder), felipechaim@hotmail.com(F. D. M. Chaim), chaim@hc.unicamp.br(É. A. Chaim)

${ }^{*}$ Corresponding author

\section{To cite this article:}

Jessica Eloa Poletto, Daniela Tezoto Rizzo, Elaine Cristina Cândido, Ana Maria Neder, Felipe David Mendonça Chaim, Elinton Adami Chaim. The Influence of Physical Activity on Quality of Life in Morbidly Obese Patients with Urinary Dysfunction. Science Journal of Public Health. Special Issue: Obesity and Physical Activity: Myths, Indications and Facts. Vol. 8, No. 3, 2020, pp. 72-76.

doi: $10.11648 /$ j.sjph.20200803.12

Received: April 27, 2020; Accepted: May 27, 2020; Published: June 3, 2020

\begin{abstract}
Obesity is a disease characterized by excess fat in the body that results in damage to health. Several cardiovascular diseases, diabetes, musculoskeletal disorders and some neoplasms are considered to be comorbidities related to obesity, as well as urinary dysfunction and, as a result, a deficit in quality of life. Adherence to physical activity can be part of the adoption of healthier lifestyles and assist in the treatment of obesity and comorbidities related to it, as well as urinary dysfunction and quality of life. Thus, the aim of the present study was to evaluate the influence of physical activity on the quality of life of morbidly obese individuals who have urinary dysfunction. This is a cross-sectional observational pilot study. The anthropometric variables collected were weight; height; Body Mass Index (BMI); and average waist circumference. The level of physical activity of the patients was assessed using IPAQ SF - International Physical Activity Questionnaire Short Form. To characterize the patients in relation to the percentage of fat, the Prediction Equation for Obese Individuals - Women was used. Urinary incontinence was assessed using the International Consultation on Incontinence Questionnaire - Short Form (ICIQ-SF). Quality of life was assessed using the questionnaire WHOQOL BREF - World Health Organization Quality of Life Assessment Bref. A total of 47 individuals were approached and evaluated, being 31 active and 16 sedentary. There was no significant correlation between the variables analyzed in the group of active individuals. However, in the group of sedentary individuals, significant negative correlations were found between BMI and quality of life general $(\mathrm{R}=-0.610 ; \mathrm{p}=0.011)$, physical domain $(\mathrm{R}=-0.642 ; \mathrm{p}=0.007)$ and psychological domain $(\mathrm{R}=-0.625$; $\mathrm{p}=0.009)$; and between percentage of fat and quality of life general $(\mathrm{R}=-0.609 ; \mathrm{p}=0.012)$, physical domain $(\mathrm{R}=-0.637$; $\mathrm{p}=0.007)$ and psychological domain $(\mathrm{R}=-0.590 ; \mathrm{p}=0.015)$. Among sedentary obese people with urinary dysfunction, a significant impairment of quality of life was registered, especially in the general scope and in the physical and psychological domains. In the group of active obese patients with urinary dysfunction, there was no significant correlation between the variables analyzed.
\end{abstract}

Keywords: Physical Activity, Quality of Life, Morbidly Obese, Urinary Dysfunction

\section{Introduction}

Obesity is a disease characterized by excess fat in the body that results in damage to health [1]. Its origin may involve genetic, endocrine, behavioral, social, economic, psychological and environmental imbalances [2].

Several cardiovascular diseases, diabetes, musculoskeletal disorders and some neoplasms are considered to be 
comorbidities related to obesity [2], as well as urinary dysfunction [3] and, as a result, a deficit in quality of life [4, $5]$.

The International Continence Society defines urinary dysfunction as any involuntary loss of urine [6]. Among risk factors (advanced age, white race, parity and number of vaginal deliveries), obesity is the one that is most related to urinary loss $[7,8]$. It is estimated that 46 to $67 \%$ of these women have urinary dysfunction [9].

According to WHOQOL Group [10] quality of life is defined as "the individual's perception of his position in life in the context of the culture and value system in which he lives and in relation to his goals, expectations, standards and concerns".

For women, in addition to hygienic discomfort (smell of urine, use of daily pads with frequent changes), urinary dysfunction determines social, sexual, psychological and economic problems [11]. Thus, urinary dysfunction has consequences for the daily activities of these patients, significantly affecting their quality of life [12].

Adherence to physical activity can be part of the adoption of healthier lifestyles and assist in the treatment of obesity and comorbidities related to it [13], as well as urinary dysfunction and quality of life.

Physical activity can be termed as any movement performed by the contraction of skeletal muscle, increasing energy expenditure when compared to rest [14].

Thus, the aim of the present study was to evaluate the influence of physical activity on the quality of life of morbidly obese individuals who have urinary dysfunction.

\section{Methods}

Study design and ethical aspects

This is a cross-sectional observational pilot study, approved by the institution's Research Ethics Committee, opinions 2.038.341 and 2.291.046. All patients signed a Free and Informed Consent Form (FICF).

Selection of participants

Participants were selected at the Bariatric Surgery Clinic at the State University of Campinas following the criteria:

Inclusion criteria

1. Obese grades III;

2. Age between 18 to 59 years;

3. Women;

4. Be the first participation in the group.

Exclusion criteria

1. Physical disability and / or functional limitation;

2. Intellectual disability;

3. Urinary tract disorders or surgery;

4. Medications that can lead or accentuate urinary incontinence;

5. Be under the tutelage of the State.

Outcome measures

Physical activity

The level of physical activity of the patients was assessed using IPAQ SF - International Physical Activity

\section{Questionnaire Short Form [15].}

Anthropometric measurements

Weight; height; Body Mass Index (BMI); and average waist circumference in centimeters $(\mathrm{CAB})$, being that $\mathrm{CAB}=$ $[(\mathrm{AB} 1+\mathrm{AB} 2) / 2]$, where $\mathrm{AB} 1$ is equivalent to the abdominal circumference in centimeters measured with reference to the midpoint between the sternum and the navel (frontal) and the midpoint between the last rib and the iliac crest (lateral) and $\mathrm{AB} 2$ is equivalent to the abdominal circumference in centimeters measured at the level of the umbilical scar [16].

Percentage of fat

To characterize the patients in relation to the percentage of fat, the Prediction Equation for Obese Individuals - Women [16] was used, which uses the measures of height (in centimeters), weight (in kilograms) and the average abdominal circumference (in centimeters) and was used, also, the calculation of Body Mass Index (BMI), to define the patient's physical condition.

Urinary incontinence

Urinary incontinence was assessed using the International Consultation on Incontinence Questionnaire - Short Form (ICIQ-SF) [17].

Quality of life

Quality of life was assessed using the questionnaire WHOQOL BREF - World Health Organization Quality of Life Assessment Bref [18].

The evaluations and questionnaires were carried out at the moment the patient entered the program and the data collection was carried out individually, with an approximate duration of 30 minutes.

Statistical analysis

The data obtained were transcribed to the BioEstat version 5.3 database in Portuguese and a descriptive analysis of the variables was performed. The Shapiro-Wilk test was used to verify the normality of the data and the Spearman correlation test, considering a significance level of $5 \%(\mathrm{p}<0.05)$.

\section{Results}

A total of 47 individuals were approached and evaluated, being 31 active and 16 sedentary.

Table 1 shows the characterization of the sample through the descriptive analysis of the results of the group of active individuals and table 2 shows the characterization of the sample through the descriptive analysis of the results of the group of sedentary individuals.

The correlation between anthropometric variables and the quality of life domains of the group of active individuals is shown in table 3 and the correlation between anthropometric variables and the quality of life domains of the group of sedentary individuals is shown in table 4.

The Figure 1 graph represents the data for the group of active individuals and the Figure 2 graph represents the data for the group of sedentary individuals. 


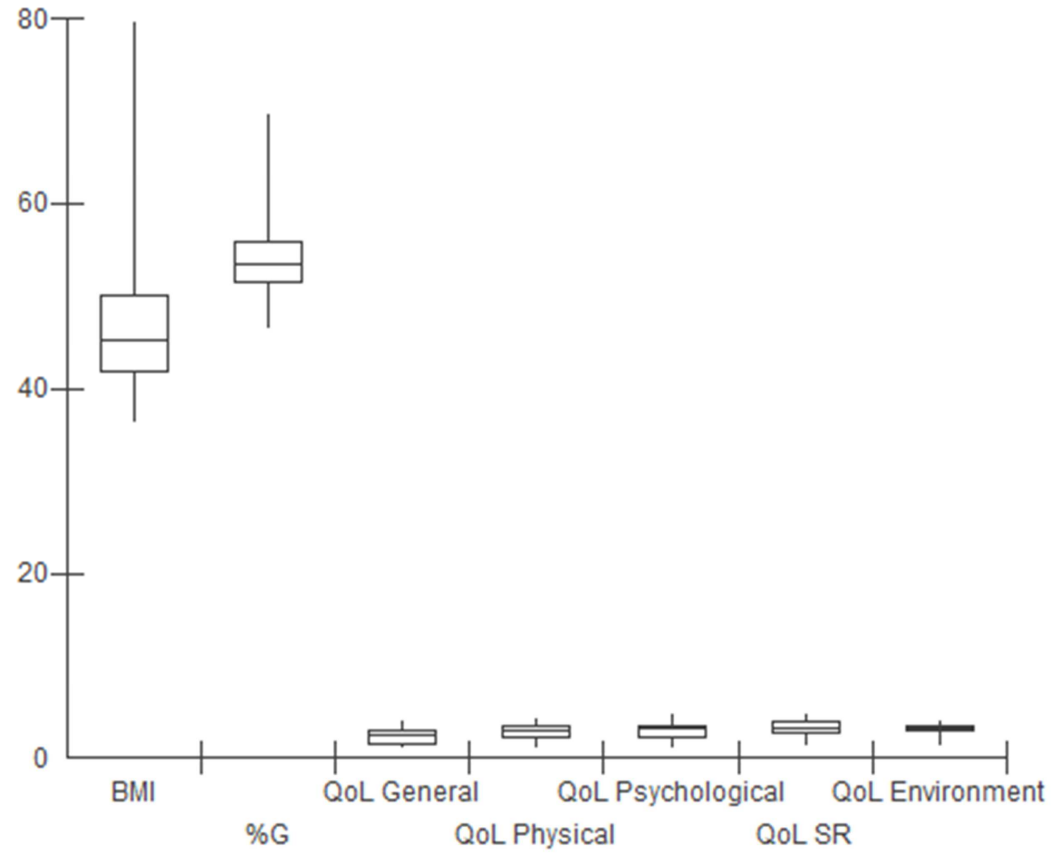

Figure 1. Data from the group of active individuals.

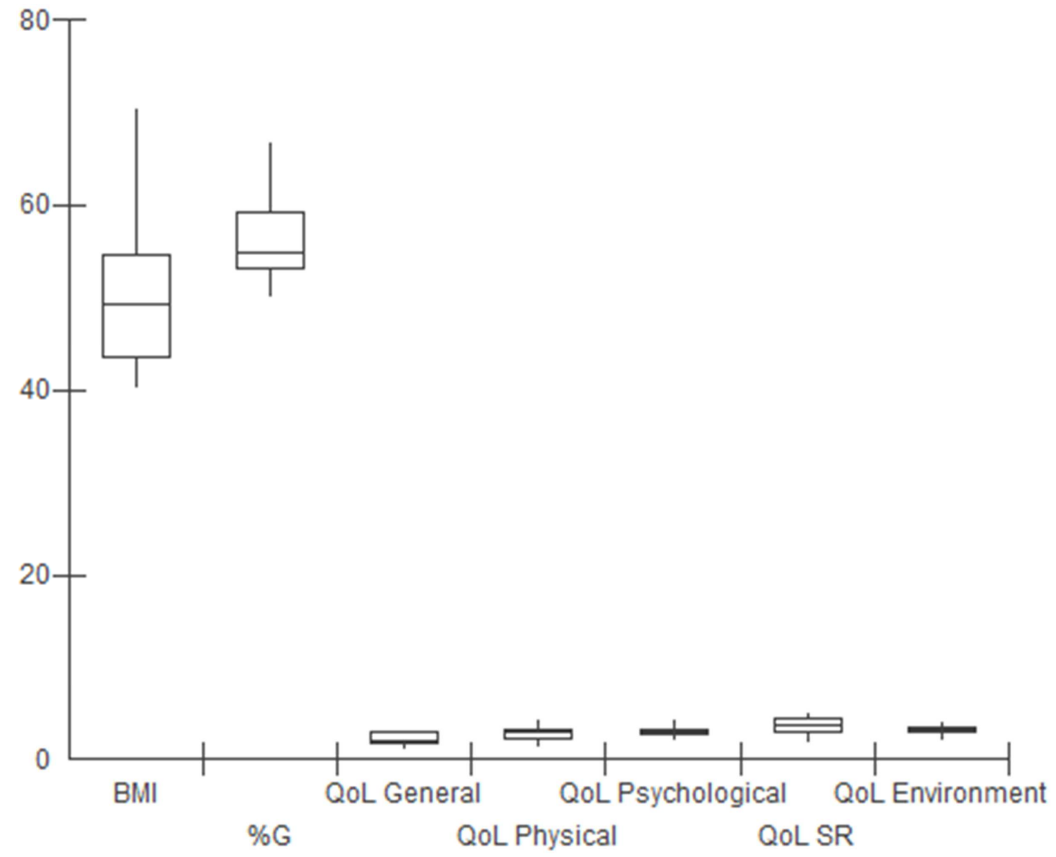

Figure 2. Data from the group of sedentary individuals.

Table 1. Descriptive analysis of the group of active individuals.

\begin{tabular}{llllllll}
\hline & BMI & \%G & QoL Gen & QoL Phys & QoL Psy & QoL SR & QoL Env \\
\hline Sample size & 31 & 31 & 31 & 31 & 31 & 31 & 31 \\
Arithmetic average & 47.068 & 54.143 & 2.4839 & 2.7553 & 2.9352 & 3.2254 & 3.0685 \\
Standard deviation & 8.4463 & 4.4789 & 0.9353 & 0.8217 & 0.773 & 0.8919 & 0.6148 \\
\hline
\end{tabular}

BMI - Body Mass Index

$\% \mathrm{G}-$ Percentage of fat

QoL Gen - Quality of life General

QoL Phys - Quality of life Physical Domain

QoL Psy - Quality of life Psychological Domain

QoL SR - Quality of life Social Relations Domain

QoL Env - Quality of life Environment Domain 
Table 2. Descriptive analysis of the group of sedentary individuals.

\begin{tabular}{llllllll}
\hline & BMI & \%G & QoL Gen & QoL Phys & QoL Psy & QoL SR & QoL Env \\
\hline Sample size & 16 & 16 & 16 & 16 & 16 & 16 & 16 \\
Arithmetic average & 50.7188 & 56.4965 & 2.2188 & 2.7853 & 3.0205 & 3.583 & 3.1172 \\
Standard deviation & 9.0803 & 4.963 & 0.7296 & 0.7825 & 0.5123 & 0.9149 & 0.4575 \\
\hline
\end{tabular}

Table 3. Correlation between anthropometric variables and the quality of life domains of the group of active individuals.

\begin{tabular}{llll}
\hline & & BMI & \%G \\
\hline \multirow{2}{*}{ QoL General } & $\mathrm{R}$ & -0.084 & -0.200 \\
& $\mathrm{P}$ & 0.649 & 0.280 \\
QoL Physical & $\mathrm{R}$ & -0.124 & -0.144 \\
QoL & $\mathrm{P}$ & 0.504 & 0.438 \\
Psychological & $\mathrm{R}$ & -0.113 & -0.138 \\
QoL SR & $\mathrm{P}$ & 0.544 & 0.457 \\
QoL & $\mathrm{R}$ & 0.019 & 0.053 \\
Environment & $\mathrm{P}$ & 0.918 & 0.775 \\
\hline
\end{tabular}

Table 4. Correlation between anthropometric variables and the quality of life domains of the group of sedentary individuals.

\begin{tabular}{llll}
\hline & & BMI & \%G \\
\hline \multirow{2}{*}{ QoL General } & $\mathrm{R}$ & -0.610 & -0.609 \\
& $\mathrm{P}$ & 0.011 & 0.012 \\
QoL Physical & $\mathrm{R}$ & -0.642 & -0.637 \\
QoL & $\mathrm{P}$ & 0.007 & 0.007 \\
Psychological & $\mathrm{R}$ & -0.625 & -0.590 \\
QoL SR & $\mathrm{P}$ & 0.009 & 0.015 \\
QoL & $\mathrm{R}$ & -0.329 & -0.291 \\
Environment & $\mathrm{P}$ & 0.213 & 0.273 \\
\hline
\end{tabular}

There was no significant correlation between the variables analyzed in the group of active individuals.

However, in the group of sedentary individuals, significant negative correlations were found between BMI and quality of life general $(\mathrm{R}=-0.610 ; \mathrm{p}=0.011)$, physical domain $(\mathrm{R}=-0.642$; $\mathrm{p}=0.007)$ and psychological domain $(\mathrm{R}=-0.625 ; \mathrm{p}=0.009)$; and between percentage of fat and quality of life general $(\mathrm{R}=$ 0.609; $\mathrm{p}=0.012)$, physical domain $(\mathrm{R}=-0.637 ; \mathrm{p}=0.007)$ and psychological domain $(\mathrm{R}=-0.590 ; \mathrm{p}=0.015)$.

\section{Discussion}

In the present study, significant negative correlations were found in the group of sedentary individuals between the BMI and the quality of life general and physical and psychological domains of quality of life; and between the percentage of fat and the quality of life general physical and psychological domains of quality of life.

In the group of active individuals, no correlations were found between anthropometric variables and quality of life, showing evidence that physical activity decreases negative impacts on daily and routine life of obese people with urinary dysfunction.

According to the literature, the study by Mourão et al. [19] assessed the prevalence of urinary complaints in 50 women over 40 years of age. Of these, $42 \%$ reported problems with urinary dysfunction, $23 \%$ of whom were obese. Obesity is the risk factor that is most associated with urinary loss $[7,8]$.

The study by Poletto et al. [20] showed that obese women with high scores for urinary dysfunction had a deficit in quality of life, directly interfering in their daily life, leading to low self-esteem and, in some cases, to depressive conditions.

In the same line of study, Brigatto, Sgariboldi and Forti [21] showed that of 65 morbidly obese women interviewed, 19 presented symptoms of urinary incontinence and consequently had a negative impact on their quality of life.

Still on obese women with urinary incontinence and the impact on quality of life, the literature review by Guedes et al. [22] presented eight articles that found significant results between obesity, urinary incontinence and impact on quality of life and two articles that did not find significant results between the same variables.

The same review [22] also presented two articles that related the decrease in urinary incontinence scores and the improvement in the quality of life domains after bariatric surgery; two articles that, after weight loss, showed improvement in urinary dysfunction and less negative impact on quality of life; an article that showed no improvement after weight loss; and two articles that worsened quality of life after surgery for stress urinary incontinence.

Although no articles were found to specifically assess the influence of the level of physical activity of obese individuals with urinary incontinence on quality of life, the results of the present study show evidence that the practice of activities is efficient to reduce negative impacts on quality of life of obese women with urinary dysfunction.

\section{Conclusion}

Among sedentary obese people with urinary dysfunction, a significant impairment of quality of life was registered, especially in the general scope and in the physical and psychological domains.

In the group of active obese patients with urinary dysfunction, there was no significant correlation between the variables analyzed, indicating, therefore, that despite being overweight and urinary complaints, the practice of physical activity reduces the negative impacts on quality of life.

\section{References}

[1] Guyton AC, Hall JE. Tratado de Fisiologia Médica. 9ed. Rio de Janeiro: Guanabara; 1997.

[2] McArdle DW, Katch FI, Katch VL. Fisiologia do Exercício: Energia, Nutrição e Desempenho Humano. 5ed. Rio de Janeiro: Guanabara Koogan S. A.; 2003. 
[3] Chmel R, Novackova M, Vlk R, Horcicka L. Epidemiological aspects of the femele urinary incontinence. Journal of Czech Physicians. 2005; 144: 95-7.

[4] Baltieri L, Martins LC, Cazzo E, Modena DAO, Gobato RC, Candido EC, Chaim EA. Analysis of quality of life among asthmatic individuals with obesity and its relationship with pulmonary function: cross-sectional study. São Paulo Medical Journal. 2017; 135 (4): 332-8.

[5] World Health Organization. Fact Sheet Obesity and Overweight. $2016 . \quad$ Disponível em $<$ http://www.who.int/mediacentre/factsheets/fs311/en/>.

[6] Abrams, P. The standardization of terminology of lower urinary tract function report from the Standardisation SubComitee of the International Continence Society. Neurourology and Urodynamics. 2002; 21 (2): 167-78.

[7] Melville JL, Katon W, Delaney K, Newton K. Urinary incontinence in US women: a population-based study. Archives of Internal Medicine. 2005; 165 (5): 537-42.

[8] Brown JS, Seeley DG, Fong J, Black DM, Ensrud KE, Grady D. Urinary incontinence in older women: who is at risk? Obstetrics \& Gynecology. 1996; 87 (5Pt1): 715-21.

[9] Gerten KA, Ritcher HE, Burgio KL, Redden DT. Impact of urinary incontinence in morbidly obese women versus women seeking urogynecologic care. Urology. 2007; 70 (6): 1082-5.

[10] WHOQOL-Group. The World Health Organization quality of life assessment (WHOQOL): Position paper from the World Health Organization. Social Science and Medicine. 1995; 10: 1403-9.

[11] Ternent L, Vale L, Buckley B, Glazener C. Measuring outcomes of importance to women with stress urinary incontinence. BJOG. 2009; 116 (5): 719-25.

[12] Dedicação AC, Haddad M, Saldanha MES, Driusso P. Comparação da qualidade de vida nos diferentes tipos de incontinência urinária feminina. Revista Brasileira de Fisioterapia. 2009; 13 (9): 5-10.
[13] Matsudo VKR. Vida ativa para o novo milênio. Revista Oxidologia. 1999; 18-24.

[14] Lazzoli JK, Nóbrega ACL, Carvalho T et al. Atividade física e saúde na infância e adolescência. Rev Bras Med Esporte. 1998; 4 (4): 107-9.

[15] Pardini R, Matsudo S, Araújo $T$, et al. Validação do questionário internacional de nível de atividade física (IPAQ versão 6): estudo piloto em adultos jovens brasileiros [Validation of the International Physical Activity Questionaire (IPAQ version 6): pilot study in Brazilian young adults]. Rev Bras Ciên Mov. 2001; 9 (3): 45-51.

[16] Heyward VH, Stolarczyk LM. Avaliação da composição corporal aplicada. São Paulo. Manole: 2000.

[17] Tamanini JTN, Dambros M, D'Ancona CAL, Palma PCR, Netto Junior NR. Validação para o português do "International Consultation on Incontinence Questionnaire - Short Form (ICIQ-SF)”. Revista de Saúde Pública. 2004; 38 (3): 438-44.

[18] WHOQOL-Group. The World Health Organization quality of life assessment (WHOQOL): Development and general psychometric properties. Social Science and Medicine. 1998b; 46: $1569-85$.

[19] Mourão FAG, Lopes LN, Vasconcellos NPC, Almeida MBA. Prevalência de queixas urinárias e o impacto destas na qualidade de vida de mulheres integrantes de grupos de atividade física. ACTA FISIATR. 2008; 15 (3): 170-5.

[20] Poletto JE, Rizzo DT, Baltieri L, Cazzo E, Chaim EA. Influência da obesidade e das medidas antropométricas sobre a incontinência urinária e a qualidade de vida: um estudo piloto. RBONE. 2018; 12 (75): 901-7.

[21] Brigatto P, Sgariboldi D, Forti EP. Qualidade de vida em mulheres obesas mórbidas com incontinência urinária. Anais 10․ Mostra Acadêmica UNIMEP. 2012.

[22] Guedes PF, Felipetto N, Frigo LF, Moraes CB, Colpo E. Sobrepeso e obesidade em mulheres com incontinência urinária e a repercussão na qualidade de vida. Disciplinarum Scientia. 2017; 18 (3): 539-50. 